\title{
Probabilistic Analysis of Space Shuttle Body Flap Actuator Ball Bearings
}

\author{
Fred B. Oswald \\ National Aeronautics and Space Administration \\ Glenn Research Center \\ Cleveland, Ohio 44135
}

Timothy R. Jett

National Aeronautics and Space Administration

Marshall Space Flight Center

Marshall Space Flight Center, Alabama 35812

Roamer E. Predmore

Swales Aerospace

Greenbelt, Maryland 20771

Erwin V. Zaretsky

National Aeronautics and Space Administration

Glenn Research Center

Cleveland, Ohio 44135 


\begin{abstract}
A probabilistic analysis, using the 2-parameter Weibull-Johnson method, was performed on experimental life test data from space shuttle actuator bearings. Experiments were performed on a test rig under simulated conditions to determine the life and failure mechanism of the grease lubricated bearings that support the input shaft of the space shuttle body flap actuators. The failure mechanism was wear that can cause loss of bearing preload. These tests established life and reliability data for both shuttle flight and ground operation. Test data were used to estimate the failure rate and reliability as a function of the number of shuttle missions flown. The Weibull analysis of the test data for a 2-bearing shaft assembly in each body flap actuator established a reliability level of 99.6 percent for a life of 12 missions. A probabilistic system analysis for four shuttles, each of which has four actuators, predicts a single bearing failure in one actuator of one shuttle after 22 missions (a total of 88 missions for a 4-shuttle fleet). This prediction is comparable with actual shuttle flight history in which a single actuator bearing was found to have failed by wear at 20 missions.
\end{abstract}

Keywords: Weibull analysis, Life prediction, Wear, Rolling element bearings, Grease lubrication

\title{
Nomenclature
}

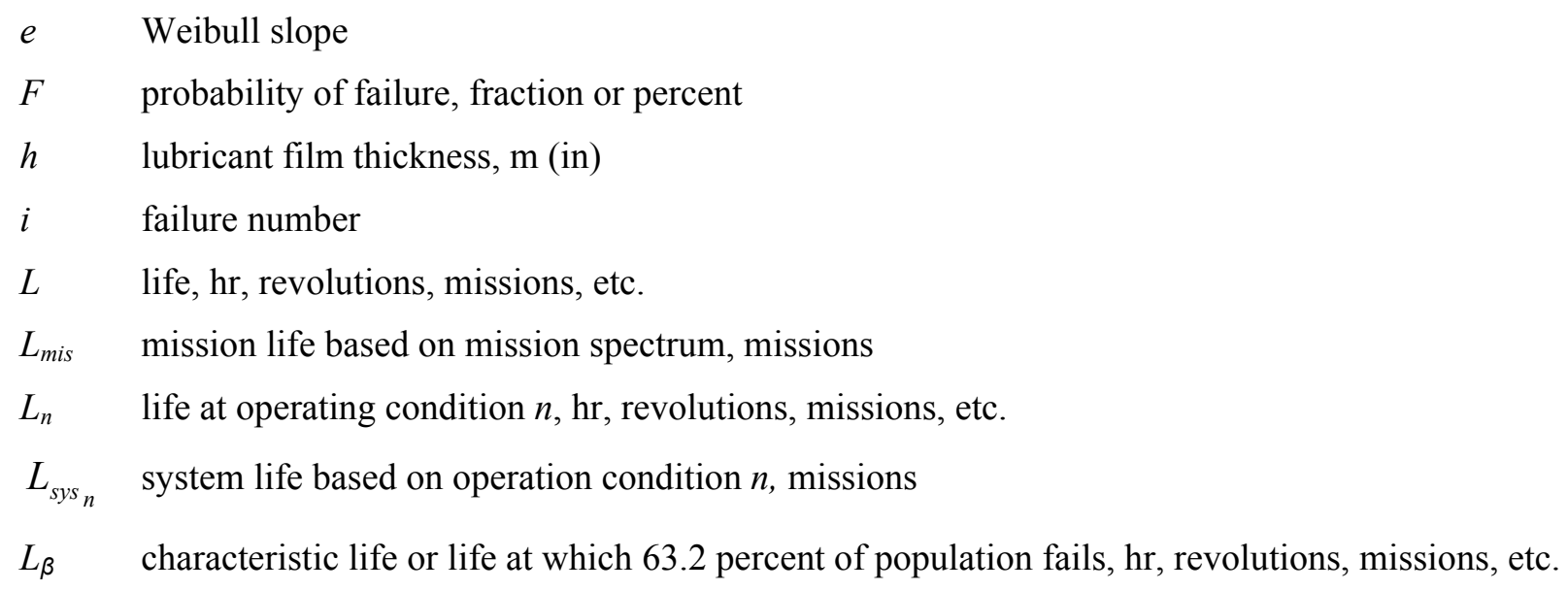


$L_{10} \quad$ 10-percent life or life at which 90 percent of a population survives, hr, revolutions, missions, etc.

$L_{1} \quad$ 1-percent life or life at which 99 percent of a population survives, hr, revolutions, missions, etc.

$L_{0.1} \quad$ 0.1-percent life or life at which 99.9 percent of a population survives, hr, revolutions, missions, etc.

$n \quad$ number of components (samples)

$S \quad$ probability of survival (reliability), fraction or percent

$S_{s y s} \quad$ probability of survival or reliability of a system of components, fraction or percent

$X_{n} \quad$ time fraction spent at operating condition $n$, fraction or percent

\section{Introduction}

Spacecraft have many components whose surfaces either oscillate or rotate slowly. Typical applications involve rolling-element bearings that support scanning mirrors, extendable booms, and the mechanical actuators for control surfaces on some reentering spacecraft. Oscillatory motion is motion in which the shaft turns in one angular direction and then returns in the same arc on either a periodic or intermittent basis. For boom oscillation, the angular velocities are generally low $(<6 \mathrm{deg} / \mathrm{s})$ and equal in both directions. For scanning mirrors the rotation in one direction is usually extremely slow $(2 \mathrm{deg} / \mathrm{s})$ followed by a rapid return ( $>60 \mathrm{deg} / \mathrm{s})$ [1]. The body flap actuators used in the space shuttle operate at input speeds to $80 \mathrm{rpm}$ against rapid deflections caused by transient aerodynamic loads during reentry.

The lubrication of spacecraft bearings is as varied as their space applications. The purpose of lubrication is to separate the surfaces in relative motion by a material that has a low resistance to shear so that the surfaces do not sustain significant damage. This low resistance material can be comprised of a variety of materials (e.g., adsorbed gases, liquids, films, chemical reaction products, or solid lubricants) [1].

Depending on the type of intervening film and its thickness, a number of lubrication regimes can be identified [1-3]. These regimes are called hydrodynamic, elastohydrodynamic, mixed, and boundary. The regimes can be defined by the approximate thickness $(h)$ of the separating film. In the hydrodynamic lubrication regime, the surfaces are completely separated by the film, $h>10^{-7} \mathrm{~m}\left(10^{-5} \mathrm{in}\right)$. The hydrodynamic regime blends into the elastohydrodynamic lubrication regime, where loads cause elastic deformation of the surfaces of the mechanism and affect the viscosity of the fluid film, $10^{-8} \leq h \leq 10^{-6} \mathrm{~m}\left(10^{--6} \leq h \leq 10^{-4} \mathrm{in}\right.$.). In the mixed lubrication regime, as the film becomes too thin to completely separate surface asperities, $10^{-9} \leq h \leq 10^{-8} \mathrm{~m}\left(10^{-7} \leq h \leq 10^{-6} \mathrm{in}\right.$. $)$. Under mixed 
lubrication, asperity interactions combine with fluid film effects to support the load as friction increases. Finally, in the boundary lubrication regime, oxide films and other impurities are needed to prevent welding of the contacting surfaces $h \leq 10^{-9} \mathrm{~m}\left(10^{-7}\right.$ in. $)$. Most space mechanisms operate in the boundary lubrication regime.

In the boundary lubrication regime, the degree of metal-to-metal contact and the wear rate increase as the load increases. Noncorrosive lubricants allow adhesive wear under boundary and mixed lubrication conditions. Under moderate loads, wear is generally mild. However very high loads create severe adhesion and surface distress (scoring). Lubricants that contain corrosive (extreme pressure and antiwear) additives can extend the boundary regime before boundary film failure begins. At this point, total surface failure occurs, followed by seizure. Besides the load, other operating variables that will affect lubricant film performance include speed, temperature, and the environment, including the ambient atmosphere [1].

A search of the literature reveals a large amount of qualitative wear data that has been generated on an assortment of laboratory testers over a period of decades. Equations and analysis exist together with friction and wear data to allow for calculating lubricant film thickness, lubrication operating regime, and the qualitative severity of the wear [4-6]. However, there is no definitive analysis that allows an engineer to predict, with any degree of engineering certainty, the quantity of wear that can occur in a specific application. Quantitative results need to be obtained experimentally for specific applications. These resulting wear data are not deterministic, but rather, statistical (distributive).

Bearing life and reliability calculations are usually based on contact fatigue of the running surfaces. In some applications, particularly where lubrication is marginal, the failure mechanism may become adhesive or abrasive wear rather than fatigue of the rolling elements and races of the bearings. Reference [7] compares tests in a vacuum spiral orbit tribometer with full-scale rig tests of instrument scanner bearings that continuously operate in dither motion. Reference [8] discusses accelerated wear testing of the bearings on small electric motors.

Reference [9] covers wear phenomena; however, its coverage of life modeling deals with fatigue failure, which becomes a source of wear debris, rather than wear itself as a failure mechanism. Most of the other reports in the literature that deal with wear life and reliability of bearings, concern the beneficial effect from filtration of liquid lubricants. Such filtration is not feasible with grease lubrication. 
The United States space shuttle has four body flap actuators (two on each wing) on a common segmented shaft. These actuators control the position of the large body flap that controls the attitude of the shuttle. During actuator refurbishment and inspection, the grease-lubricated ball bearings in these actuators exhibited various degrees of wear. Given the observed wear, the question arises regarding the timing for removal of the actuators for refurbishing. To put it concisely, how many space shuttle flights should be allowed before the actuators are removed and refurbished because of wear of the actuator bearings?

Based on the above discussion, the objectives of the work reported herein were to: (a) experimentally duplicate the operating conditions of the space shuttle body flap actuator input shaft ball bearings; (b) generate, under these simulated conditions, a statistical data base codifying bearing wear; (c) determine the usable life of the actuator bearings based on a two-parameter Weibull distribution function for the bearings using strict-series system reliability; and (d) compare these results to field data from the space shuttle fleet.

\section{Apparatus, Specimens, and Procedure}

\section{Body Flap Actuator Bearings}

Each of the four body flap actuators (shown in cross section in Fig. 1) is a two stage, differential planetary gearbox with a speed reduction ratio of 162:1. The actuator input shaft acts as a tension rod to clamp the actuator housing together.

The shaft is supported by two angular contact ball bearings that carry a heavy axial (thrust) preload of $16 \mathrm{kN}(3,500 \mathrm{lb})$. The smaller shaft bearing is a full complement, 106-size (30-mm bore) deep-groove ball bearing containing 18 balls of $7.14 \mathrm{~mm}$ (0.281 in.) diameter. The larger bearing is a full complement, 108-size (40-mm bore) deep-groove ball bearing containing 21 balls of $7.94 \mathrm{~mm}(0.3125 \mathrm{in}$.) diameter. These bearings are made from carbon vacuum degassed (CVD) AISI 52100 steel.

When the transient aerodynamic load is added, the total bearing load can reach $22 \mathrm{kN}(5,000 \mathrm{lb})$ Because of these high loads, the contact stress is very high—up to $3.41 \mathrm{GPa}$ (495 ksi) on the smaller 106-size bearing and $3.03 \mathrm{GPa}(440 \mathrm{ksi})$ on the 108 -size bearing. With this high load, the ball running track extends nearly to the shoulder of the bearing inner races. 
The actuator performs oscillatory motion during reentry from body flap actuation against transient aerodynamic loads with input speeds as high as $80 \mathrm{rpm}$.

\section{Lubricant}

The mechanical actuators used on the space shuttle are lubricated by a space-rated, grade 2 grease containing a perfluorinated polyether base oil with small polytetrafluoroethylene (PTFE) particles as a thickener, and sodium nitrite and dimethyloctyldecylbenzyl ammonium bentonite as rust and corrosion inhibitors. The grease has a wide operating temperature range: -80 to $204{ }^{\circ} \mathrm{C}$. The viscosity of the lubricant base oil at the three temperatures used for this test program $\left(24,60\right.$, and $\left.74{ }^{\circ} \mathrm{C}\right)$ is approximately $4,750,128$, and $77 \mathrm{cSt}$, respectively. The grease does not contain reactive extreme pressure additives that are typically added to hydrocarbon grease because these additives will not dissolve in the base oil [10].

\section{Test Apparatus and Procedure}

Tests were conducted at NASA Marshall Space Flight Center on angular-contact ball bearings representative of the smaller (106-size) bearings used on the input shaft of the space shuttle body flap actuators [11]. The tests were conducted in air under axial loads between 16 and $22 \mathrm{kN}$, at ambient temperatures of $24{ }^{\circ} \mathrm{C}$ $\left(75^{\circ} \mathrm{F}\right)$ to $74^{\circ} \mathrm{C}\left(165^{\circ} \mathrm{F}\right)$, and at speeds between 50 and $80 \mathrm{rpm}$.

The bearing life test rig (shown in Fig. 2) uses an electric motor and belt drive to rotate the bearing shaft. The bearing housings are axially guided on parallel shafts to hold close alignment. The axial preload acting on the bearings was manually set with a mechanical screw actuator. The axial load was measured by a load cell and monitored by a computer, which automatically terminated the test if the load dropped by $1.3 \mathrm{kN}$. The drive belt creates a small radial load on the bearings, about 10 percent of the axial load. The loading conditions are similar to those in the actuator under flight conditions.

The bearing housing temperature was controlled by circulating ethylene glycol through passages in the bearing test housings to raise the test bearing temperature to 60 or $74{ }^{\circ} \mathrm{C}$ for the elevated temperature tests. Thermocouples on the outer races monitored the bearing temperatures. 
Test bearings included three used flight bearings that had been removed from flight actuators. These were supplemented with 106-size commercial bearings modified to be similar to the full complement bearings used in flight actuators. The bearings were lubricated by perfluorinated polyether oil-based grease as is used in the space shuttle actuators.

A bearing test spectrum, based on the original actuator life mission spectrum, was developed to demonstrate that worn shuttle bearings could operate for 48 flight missions after cleaning and relubrication. This would indicate a life of 12 missions with a $4 \mathrm{X}$ safety factor. The life mission spectrum was based on a compressed version of the shuttle loads analysis. Table 1 shows the run time, speed, load, and calculated inner race Hertz stress for each condition of the mission spectrum. Stresses were calculated by the Shaberth bearing analysis program [12]. In the initial bearing life testing, this spectrum was repeated 48 times in a 24 hour period for a total of 112,800 revolutions per test.

The test program produced a total of 18 bearing failures out of 38 bearings tested, where failure was defined by loss of preload ( of $1.3 \mathrm{kN}$ ). The failures occurred in nearly equal numbers from the two bearing mounts on the test device (see Fig. 2), eight failures near the load application side and ten at the load reaction side (near the load cell).

Later reexamination of the shuttle mission time line by the NASA Engineering and Safety Center (NESC) established the actual operation time to be only 13.1 minutes per mission at the normal speed of $80 \mathrm{rpm}$ (1048 rev/mission). This was allocated as 35 seconds of flight operation at $60{ }^{\circ} \mathrm{C}$ temperature and 12.5 minutes of ground operations $\left(24^{\circ} \mathrm{C}\right)$. The bearing life and reliability results reported here have been adjusted to be consistent with the revised mission time.

\section{Statistical Analysis}

\section{Weibull Analysis}

In 1939, W. Weibull [13-15] developed a method and equation for statistically evaluating the fracture strength of materials. He also applied the method and equation to fatigue data based upon small sample 
(population) sizes, where the two-parameter expression relating life, $L$, characteristic life, $L_{\beta}$ and probability of survival, $S$ is

$$
\ln \ln \left(\frac{1}{S}\right)=e \ln \left(\frac{L}{L_{\beta}}\right) \text { where } 0<L<\infty ; 0<S<1
$$

When plotting the $\ln \ln [1 / S]$ as the ordinate against the $\ln L$ as the abscissa, fatigue data are assumed to plot as a straight line (Fig. 3). The ordinate $\ln \ln [1 / S]$ is graduated in statistical percent of components failed or removed for cause as a function of $\ln L$, the $\log$ of the time or cycles to failure. The tangent of the line is designated the Weibull slope $e$, which is indicative of the shape of the cumulative distribution or the amount of scatter of the data. The method of using the Weibull distribution function for data analysis for determining component life and reliability was later developed and refined by L.G. Johnson $[16,17]$. This method was used to analyze the wear data reported herein.

\section{System Life Prediction}

The reliability (or probability of survival), $S$ and the probability of failure, $F$ are related by $F=(1-S)$. For a given time or life, the reliability $S_{s y s}$ of a system is the product of the reliabilities $S_{i}(i=1,2, \ldots, n)$ of the components in the system, as shown in Eq. (2):

$$
S_{s y s}=S_{1} \times S_{2} \times \cdots \times S_{n}
$$

If all components have the same reliability $S_{n}$ (as is assumed here), then (2) reduces to

$$
S_{s y s}=S_{n}^{n}
$$

Each actuator has two input bearings and each shuttle has four actuators for a total of eight bearings. Thus, for one shuttle, Eq. (3) can be written as 


$$
S_{s y s}=S_{n}^{8}
$$

From Eq. (1), the lives of each of the bearings at a specified reliability can be combined to determine the calculated system $L_{s y s}$ life using the two-parameter Weibull distribution function (Eq. (1)) for the bearings comprising the system and strict-series system reliability [18-20] as follows:

$$
\frac{1}{L_{s y s}^{e}}=\left(\frac{1}{L_{1}^{e_{1}}}+\frac{1}{L_{2}^{e_{2}}}+\cdots \frac{1}{L_{n}^{e_{n}}}\right)
$$

In this work, the two shaft bearings are assumed to have the same life- the life of the smaller (size 106) bearing. In addition, the four actuators are assumed to have equal lives. This means that each of the bearings will have the same life at a specified reliability, where $L_{1}=L_{2}=\ldots L_{n}$ and $e_{1}=e_{2}=\ldots e_{n}$. Accordingly, Eq. (5) can be written for the eight bearings in four actuators as

$$
\frac{1}{L_{s y s}^{e}}=\left(\frac{8}{L^{e_{n}}}\right)
$$

The calculated system life is dependent on the resultant value of the system Weibull slope $e$. For wear data, this value is normally not known with certainty, but a reasonable value can be assumed from the Weibull plots of the resultant wear data.

The bearing system life of the actuators is calculated for each operating condition of their mission profile. In order to obtain the mission life of the actuators, the resulting system lives for each of the operating conditions are combined in equation (7) using the linear damage (Palmgren-Langer-Miner) rule [18-20] where $L_{s y s_{n}}$ is the life for condition $n$ and $X_{n}$ is the time fraction spend at condition $n,(n=1,2, \ldots)$. 


$$
\frac{1}{L_{m i s}}=\frac{X_{1}}{L_{s y s_{1}}}+\frac{X_{2}}{L_{s y s_{2}}}+\cdots \frac{X_{n}}{L_{s y s_{n}}}
$$

\section{Results and Discussion}

During actuator refurbishment and inspection, the grease-lubricated ball bearings in these actuators exhibited various degrees of wear. While a bearing exhibiting significant wear may continue to function over an extended time period, it is considered no longer fit for its intended application and, hence, failed.

As the bearing preload continues to decline due to increasing wear, the actuator can eventually be rendered inoperable. In the absence of a viable lubricating film, the worn contacting surfaces can experience adhesive wear, possibly leading to seizure of the mating bearing surfaces. Based upon these observations, an issue arises regarding the time to removal of the actuators for refurbishing and replacement of the bearings.

There have been 116 shuttle flights in the history of the program from 1981 to 2006. Actual space shuttle maintenance history shows that one body flap actuator bearing has been replaced due to excessive wear during the history of shuttle flights (Fig. 4). The failure was found after 20 missions on the affected vehicle. In addition, another actuator bearing was removed after 20 flights due to formation of a black iron oxide coating, apparently caused by decomposition of the lubricant. However, this bearing had only nominal wear.

In an effort to determine the life and failure mechanism of the grease-lubricated bearings that support the input shaft of the body flap actuators, life tests were performed on a test rig under simulated flight and ground operations conditions. The damage to the inner race of one of the failed test bearings is shown in Fig. 5. The damage appears similar to that of the failed flight bearing shown in Fig. 4.

A probabilistic analysis using the 2-parameter Weibull-Johnson method was performed on the life test data generated by these experiments. The tests and analysis established life and reliability data for both shuttle flight and ground operation as a function of the number of shuttle missions flown. 
The bearing lives were calculated using the 2-parameter Weibull-Johnson method for reliabilities of 99.9, 99.0, and 90 percent. In the test series presented below, we combined results of tests that gave similar lives in order to present larger data sets, even though some tests were run under somewhat different conditions.

Tables 2-5 summarize the results from four series of tests described below in terms of lives $L_{10}, L_{1}$, and $L_{0.1}$. The $L_{10}$ life is the time (in terms of the number of bearing revolutions) at which 10 percent of a population of bearings can be expected to fail (or 90 percent not to fail). Likewise, $L_{1}$ represents the time to fail 1 percent and $L_{0.1}$ is the time to failure for 0.1 percent.

The life is also given in terms of missions, assuming the revised NESC mission length of 1048 shaft revolutions (13.1 minutes). The reliability for the entire system will be the product of the reliabilities in all components comprising the system, including the other six bearings in the actuator not considered here. The system reliability will always be less than the reliability of the lowest-lived component of the system.

Bearing wear data were obtained for four series of operating conditions. The test series are described below.

\section{Test Series 1, Mission Spectrum at $60^{\circ} \mathrm{C}$}

These tests used the original, simplified, shuttle program 30-minute mission spectrum shown in Table 1. The mission spectrum was intended to represent the actual loads and speeds the actuator experiences during flight and ground operations. In this series, the bearings were heated to an ambient temperature of $60{ }^{\circ} \mathrm{C}$ to simulate the flight environment at shuttle reentry; however the tests were conducted at atmospheric pressure. Test articles included three used flight bearings plus three commercial bearings modified to be similar to the flight bearings. All six bearings completed 48 simulated missions (112,800 revolutions) with no failures (i.e., six runouts). Since there were no failures, Weibull analysis cannot be performed on these data.

\section{Test series 2 , mission spectrum at $24^{\circ} \mathrm{C}$}

These tests used the same mission spectrum as above except the bearings were not heated (ambient temperature of $24^{\circ} \mathrm{C}$ ). Only modified commercial bearings were used because no more used flight bearings were 
available. These tests were run until one of the bearings in the rig failed, thus producing three failures out of six bearings tested.

The Weibull analysis of series 2 tests gives an $L_{10}$ (90 percent reliability) life of 62,000 revolutions. The results are shown in Table 2 and Fig. 6 . Based on these data and using the revised mission time (1,048 revolutions), the reliability of one bearing for a life of 12 shuttle missions is 99.8 percent. For the eight input shaft bearings (assumed to have identical lives) in four actuators on one shuttle, the risk of failure would be 1.4 percent (reliability 98.6 percent).

The Weibull plots in Figs. 6 to 9 include 90 percent confidence bands for the data. If a large number of similar tests were performed, one would expect that 90 percent of the data would lie within these confidence bands.

\section{Combination of test series 1-2}

The data from both series above were combined to produce a Weibull plot that represents all of the mission spectrum tests at both elevated and room temperatures (12 bearings tested with three failures). The Weibull analysis on this combined set gives an $L_{10}$ (90 percent reliability) life of 80,000 revolutions. The results are shown in Table 3 and Fig. 7. (Runout tests were included in the analysis but are not shown in the figure.)

The analysis shows the reliability of one bearing for a life of 12 missions is 99.95 percent. For the eight input shaft bearings (assumed to have identical lives) in four actuators on one shuttle, the risk of failure would be 0.4 percent (reliability 99.6 percent).

\section{Test series 3, constant speed tests at $24^{\circ} \mathrm{C}$ constant temperature, load $16-24 \mathrm{kN}, 50$ and $80 \mathrm{rpm}$}

Tests were conducted at room temperature $\left(24^{\circ} \mathrm{C}\right)$ with loads of 16,20 , and $22 \mathrm{kN}$ and speeds of 50 and $80 \mathrm{rpm}$. The differences in speeds and loads had little effect on the lives for the limited range tested; hence, smaller data sets were combined together. Results are shown in Table 4 and Fig. 8.

Some tests of this series were restarted after a failure by replacing the failed bearing and continuing the test with the surviving bearing. In one test, both bearings failed at approximately the same time. Twenty bearings were tested with 12 failures. 
Based on these data, the reliability of one bearing for a life of 12 missions is 99.6 percent. For the eight input shaft bearings (assumed to have identical lives) in four actuators on one shuttle, the risk of failure would be 3.4 percent (reliability 96.6 percent).

\section{Test Series 4, Tests at Elevated Temperature 60 and $74{ }^{\circ} \mathrm{C}, 16 \mathrm{kN}$ Load, 50 and $80 \mathrm{rpm}$}

Three bearing failure tests (with three runout tests of the bearings at the other end of the shaft) were conducted at elevated temperature (two at $60^{\circ} \mathrm{C}$ and one at $\left.74^{\circ} \mathrm{C}\right)$. The tests were run at constant speed $(50$ or $80 \mathrm{rpm}$ ) and an axial load of $16 \mathrm{kN}$. As in series 3 above, there was little difference in lives found between these two temperatures and two speeds; therefore, results were combined. Results are shown in Table 5 and Fig. 9.

Based on these data, the reliability of one bearing for a life of 12 missions is 99.9 percent. For the eight input shaft bearings (assumed to have identical lives) in four actuators on one shuttle, the risk of failure would be 0.5 percent (reliability 99.5 percent).

\section{Bearing Wear}

In general, the test temperature was found to have the greatest effect on the lives of the bearings, with lower temperature (room temperature) tests giving shorter life. This result of lower life at lower test temperatures was not expected. It may have been caused by lubricant starvation, because the cooler oil flowed back into the contact area at a slower rate after ball passage.

One method to determine bearing wear is to accurately weigh cleaned bearings before and after a test and subtract the two readings. This method suffers from the limitation that it does not detect material transferred from one surface to another in addition to the problem of subtracting two nearly-equal numbers.

The bearings tested here were not weighed prior to testing. Cleaned, failed bearings were weighed and compared with cleaned, new bearings of the same type. These indicate an average loss of about $180 \mathrm{mg}$ or about 0.16 percent. However, the new bearings showed a much greater variation in weight from heaviest to lightest ( 0.60 percent) than the variation between new and failed bearings.

Bearing failure during tests was marked by a transition from stable bearing temperature and load to increasing temperature and declining preload. These failures were caused by the normal wear under boundary 
lubrication shifting to accelerated wear induced by lubricant breakdown. One test (at $50 \mathrm{rpm}$ ) was continued for four additional hours after the onset of severe wear. (This represents 11.5 additional missions at 1048 inner race revolutions each). The extended run created severe wear damage in which about 75 percent of the preload was lost due to wear.

After the onset of severe wear, these bearings would no longer be fit for their intended use. However, the very gradual onset of this failure mode indicates that imminent seizure is unlikely. Thus, bearing failure should not cause a failure of the actuator that would endanger the space shuttle as long as a reasonable inspection schedule is followed.

\section{Estimated System Life and Reliability}

The mission life of these bearings under combined ground and flight operation was predicted by combining the results of Series 3 (representing ground operation temperature) and Series 4 (representing flight) according to the linear damage rule. NESC Analysis of the records of the shuttle fleet has established an average operation time of 13.1 minutes per mission. This consists of 35 seconds of flight operation at an assumed temperature of $60{ }^{\circ} \mathrm{C}$ and 12.5 minutes of ground operations at $24{ }^{\circ} \mathrm{C}$. Assuming a normal operation speed of $80 \mathrm{rpm}$, there will be 1048 revolutions per mission. The 13.1 minutes operation time is less than half the 30 minutes initially assumed by the NESC.

The mission life and reliability for the 13.1 minute combined operation time were predicted by combining the results of the tests summarized in Series 3 and 4 above in proportion to the operation time, according to the linear damage rule of Eq. (7)

$$
\frac{1}{L}=\frac{X_{1}}{L_{1}}+\frac{X_{2}}{L_{2}}
$$

where $L$ is the life, $X_{1}$ and $X_{2}$ are the time fractions $\left(X_{1}+X_{2}=1.00\right)$ that occur at conditions 1 and 2 and $L_{1}$ and $L_{2}$ are the lives for these conditions. Using the data for 90 percent reliability from Series 3 and 4, Eq. (8) becomes 


$$
\frac{1}{L}=\frac{0.045}{110}+\frac{0.955}{39}=\frac{1}{40} \text { thus } L=40
$$

The predicted $L_{10}$ and $L_{0.1}$ lives for combined 24 and $60^{\circ} \mathrm{C}$ operations is 40 and 7 missions, respectively. The reliability of a single bearing for a life of 12 missions is 99.6 percent. Each actuator has two input bearings and each shuttle has four actuators, thus, from Eq. (3) above, based on four actuators and eight bearings of equal life, per shuttle,

$$
S_{\text {sys }}=S_{n}^{n}=(0.996)^{8}=0.969 \text { or } 96.9 \text { percent }
$$

Therefore, the risk of an input shaft bearing failure would be 3.1 percent (reliability 96.9 percent) for 12 missions of one shuttle (assuming all input shaft bearings have identical reliability). The relation between reliability, number of bearings involved and number of flights is shown in Fig. 10.

\section{Predicted Failure Rate for Actuator Input Shaft Bearings}

As a final way to present body flap actuator input shaft bearing test data, we relate the bearing reliability found from this test program to the expected failure rate as a function of the number of flights for the space shuttle fleet.

We used the eight bearing reliability level presented in the previous section (96.9 percent). This reliability is for 12 shuttle flights using the combined mission profile discussed above (35 seconds of flight and 12.5 minutes ground operation). We assumed the Weibull slope (2.739) as found for the $24{ }^{\circ} \mathrm{C}$ tests and, using Eq. (1), computed the characteristic life to be 42.4 missions for one bearing failure in one vehicle of the fleet. (The characteristic life is the time at which 63.2 percent of a large number of identical vehicles would have a failure.)

We assumed the following scenario: The fleet starts out with four new shuttle vehicles. These are each flown in turn until a bearing failure occurs. (No other failures are considered, only in body flap actuator input shaft bearings.) Then the shuttle with a failed bearing is retired and the remaining shuttles continue to fly until an input bearing has failed in each of the four shuttles. In this calculation, the reliability, $S(t)$ was estimated from the 
median rank of the failures, according to Eq. (11) [21], where $i$ is the failure number and $n$ is the number of samples (in this case, $n=4$ ):

$$
F \approx \frac{i-0.3}{n+0.4}
$$

The resulting number of missions in terms of the median life is shown in Table 6 . We predict that the first failure will occur at about the 22 nd mission of the first shuttle vehicle involved. If all four vehicles at that time have the same number of flights, the total number of flights will be 88 . Then we assume the remaining three vehicles continue to fly until the second failure occurs at flight 33 on another shuttle. At that time, the fleet will have 121 missions [22+(3×33)]. Likewise, failure number three occurs at flight 42 or fleet mission 139 $[22+33+(2 \times 42)]$ and the final failure at flight 53 , or fleet mission $150(22+33+42+53)$.

Actual space shuttle maintenance history shows that one body flap actuator bearing has been replaced due to excessive wear during the history of shuttle flights through 2006. The failure was found after 20 missions on the affected vehicle. In addition, another actuator bearing was removed after 20 flights due to a black iron oxide coating, apparently caused by decomposition of the lubricant. However, there was only nominal wear associated with the bearing having the blackened ball.

The one historical failure due to wear at 20 missions is consistent with the results of Table 6 , which predicts the first failure at 22 missions. Since there have been 116 flights in the history of the program through 2006, the analysis indicates another failure might have been expected soon in the absence of inspection and bearing replacement.

\section{Summary of Results}

The United States space shuttle has four body flap actuators (two on each wing) on a common segmented shaft to control the position of the large body flap on the space shuttle. During actuator refurbishment and inspection, the grease-lubricated ball bearings in these actuators exhibited various degrees of wear. Bearing tests were performed to experimentally duplicate the operating conditions of the space shuttle actuator ball bearings 
and to generate a statistical data base to codify the wear in these bearings. The usable life and reliability of these actuator bearings were determined based on a two-parameter Weibull distribution function using strict-series system reliability for both shuttle flight and ground operation as a function of the number of shuttle missions flown. These experimental results were compared to field data from the space shuttle fleet. The following results and conclusions were obtained:

1. The actuator bearing failure mechanism was severe wear that created the onset of bearing preload loss. After the onset of severe wear, the bearings would no longer be fit for their intended use. However, the very gradual onset of this failure mode indicates that imminent seizure is unlikely. Thus, bearing failure should not cause a failure of the actuator and endanger the space shuttle as long as a reasonable inspection schedule is followed.

2. The Weibull analysis of the test data for a 2-bearing shaft assembly established a reliability level of 99.6 percent for a single shuttle over a life of 12 missions.

3. A reasonable inspection and maintenance program of the body flap actuators should be implemented to enable safe operation of the shuttle orbiter fleet. This interval should not be more than 12 flights for any shuttle vehicle.

4. A probabilistic system analysis for four shuttles, each of which has four actuators, predicts a single bearing failure in one actuator of one shuttle after 22 missions. (This means a total of 88 missions for a 4-shuttle fleet.) This prediction is comparable with actual shuttle flight history in which a single actuator bearing was found to have failed by wear at 20 missions. Since there have been 116 flights in the history of the program through 2006, the analysis indicates another failure might have been expected soon in the absence of inspection and bearing replacement.

\section{References}

1. Zaretsky, E.V., ed. (1997), "Tribology for Aerospace Applications," STLE SP-37, Society of Tribologists and Lubrication Engineers, Park Ridge, IL, pp. 683-705.

2. Ertel, A.M. (1939), "Hydrodynamic Lubrication Based on New Principles," Prikadnaya Matematika I Mechanika (in Russian), 3, 2. 
3. Grubin, A.N. (1949), "Fundamentals of the Hydrodynamic Theory of Lubrication of Heavily Loaded Cylindrical Surfaces," Investigation of the Contact Machine Components, Kh. F. Ketova, ed., translation of Russian Book No. 30, Central Scientific Institute of Technology and Mechanical Engineering, Moscow (Available from Dept. of Scientific and Industrial Research, Great Britain, Trans. CTS-235, and from Special Libraries Association, Chicago, Transl. R-3554.).

4. Bhushan, B., ed. (2000), Modern Tribology Handbook, Vol. 1, CRC Press, Boca Raton, FL.

5. MacGregor, C.W. (1964), Handbook of Analytical Design for Wear, Plenum Press, NY.

6. Booser, E.R., ed. (1983), CRC Handbook of Lubrication: Theory and Practice of Tribology, Volume II: Theory and Design, CRC Press, Boca Raton, FL.

7. Jansen, M.J., Jones, W.R., Jr., Predmore, R.E., and Loewenthal, S.L. (2001), "Relative Lifetimes of Several Space Liquid Lubricants Using a Vacuum Spiral Orbit Tribometer (SOT)," NASA/TM—2001210966.

8. Wang, W. and Dragomir-Daescu, D. (2002), "Reliability Quantification of Induction Motors-Accelerated Degradation Testing Approach," in Proc. of the Reliability and Maintainability Symposium, Seattle, WA.

9. Roylance, B.J., Williams, J.A., and Dwyer-Joyce, R. (2000), "Wear Debris and Associated Wear Phenomena-Fundamental Research and Practice," Proc. Instn. Mech. Engrs.,Pt. J J. Eng. Tribol., 24, 1, pp. $79-105$.

10. Carre, David J. (1988), "The Performance of Perfluoropolyalkylether Oils Under Boundary Lubrication Conditions," Trib. Trans., 31, 4, pp. 437-441.

11. Jett, T.R, Predmore, R.E., Dube, M.J., and Jones, W.R., Jr. (2006), "Space Shuttle Body Flap Actuator Bearing Testing for NASA Return to Flight, " in Proc. of the 38th Aerospace Mechanisms Symposium, NASA/CP-2006-214290, pp. 253-268.

12. Hadden, G.B., Kleckner, R.J., Ragen, M.A., and Sheynin, L. (1981), "Research Report: User's Manual for Computer Program AT81y003 SHABERTH," in Steady State and Transient Thermal Analysis of a Shaft Bearing System Including Ball, Cylindrical and Tapered Roller Bearings, NASA CR-165365. 
13. Weibull, W. (1939), "A Statistical Theory of the Strength of Materials," Ingeniorsvetanskapsakad. Handl., 151.

14. Weibull, W. (1939), "The Phenomenon of Rupture in Solids," Ingeniorsvetanskapsakad. Handl., 153.

15. Weibull, W. (1951), "A Statistical Distribution Function of Wide Applicability," J. Appl. Mech., 18, 3, pp. 293-297.

16. Johnson, L.G. (1951), "The Median Ranks of Sample Values in Their Population with an Application to Certain Fatigue Studies," Ind. Math., 2, pp. 1-9.

17. Johnson, L.G. (1964), The Statistical Treatment of Fatigue Experiments, Elsevier Publishing Co., Amsterdam.

18. Palmgren, A. (1924), "The Service Life of Ball Bearings," Zectsckrift des Vereines Deutscher Ingenieure, 68, 14, pp. 339-341.

19. Langer, B.F. (1937), "Fatigue Failure From Stress Cycles of Varying Amplitude," ASME J. Appl. Mech., 59, pp. A160-A162.

20. Miner, M.A. (1945), "Cumulative Damage in Fatigue," J. Appl. Mech., 12, 3, pp. A159-A164.

21. NIST/SEMATECH e-Handbook of Statistical Methods, http://www.itl.nist.gov/div898/handbook/ (2006). 
TABLE 1.-BEARING TEST MISSION SPECTRUM

\begin{tabular}{|c|c|c|c|}
\hline $\begin{array}{c}\text { Time, } \\
\text { minutes }\end{array}$ & $\begin{array}{c}\text { Speed, } \\
\text { rpm }\end{array}$ & $\begin{array}{c}\text { Axial load } \\
\mathrm{kN},(\mathrm{lb})\end{array}$ & $\begin{array}{c}\text { Inner race Hertz stress } \\
\mathrm{GPa},(\mathrm{ksi})\end{array}$ \\
\hline 27 & 80 & $16(3500)$ & $3.13(452)$ \\
\hline 1.5 & 70 & $18(4100)$ & $3.27(473)$ \\
\hline 1.0 & 60 & $20(4500)$ & $3.37(486)$ \\
\hline 0.5 & 50 & $22(5000)$ & $3.41(495)$ \\
\hline
\end{tabular}


TABLE 2.-TEST SERIES 2, MISSION SPECTRUM TESTS AT $24{ }^{\circ} \mathrm{C}$ WEIBULL SLOPE, $e=2.556$, CHARACTERISTIC LIFE, $\beta=148,693 \mathrm{rev}$.

\begin{tabular}{|c|c|c|c|}
\hline Life & Reliability & Revolutions & Missions \\
\hline$L_{10}$ & $90 \%$ & 62,000 & 59 \\
\hline$L_{1}$ & $99 \%$ & 25,000 & 23 \\
\hline$L_{0.1}$ & $99.9 \%$ & 10,000 & 10 \\
\hline
\end{tabular}


TABLE 3.-TEST SERIES 1-2 (COMBINED), MISSION SPECTRUM TESTS AT $60^{\circ} \mathrm{C}$ AND $24^{\circ} \mathrm{C}$ WEIBULL SLOPE, $e=2.931$, CHARACTERISTIC LIFE, $\beta=172,866 \mathrm{rev}$.

\begin{tabular}{|c|c|c|c|}
\hline Life & Reliability & Revolutions & Missions \\
\hline$L_{10}$ & $90 \%$ & 80,000 & 77 \\
\hline$L_{1}$ & $99 \%$ & 36,000 & 34 \\
\hline$L_{0.1}$ & $99.9 \%$ & 16,000 & 16 \\
\hline
\end{tabular}


TABLE 4.-TEST SERIES 3, CONSTANT SPEED AND LOAD TESTS AT $24{ }^{\circ} \mathrm{C}, 16-24 \mathrm{kN}, 50$ AND $80 \mathrm{rpm}$ WEIBULL SLOPE, $e=2.739$, CHARACTERISTIC LIFE, $\beta=91,798$ rev.

\begin{tabular}{|c|c|c|c|}
\hline Life & Reliability & Revolutions & Missions \\
\hline$L_{10}$ & $90 \%$ & 40,000 & 39 \\
\hline$L_{1}$ & $99 \%$ & 17,000 & 16 \\
\hline$L_{0.1}$ & $99.9 \%$ & 7,400 & 7 \\
\hline
\end{tabular}


TABLE 5.-TEST SERIES 4, ELEVATED TEMPERATURE TESTS AT $16 \mathrm{kN}$ LOAD, 50 AND $80 \mathrm{rpm}$ WEIBULL SLOPE, $e=2.334$, CHARACTERISTIC LIFE, $\beta=301,729$ rev.

\begin{tabular}{|c|c|c|c|}
\hline Life & Reliability & Revolutions & Missions \\
\hline$L_{10}$ & $90 \%$ & 115,000 & 110 \\
\hline$L_{1}$ & $99 \%$ & 42,000 & 40 \\
\hline$L_{0.1}$ & $99.9 \%$ & 16,000 & 15 \\
\hline
\end{tabular}


TABLE 6.-PREDICTED FAILURE RATE FOR ACTUATOR INPUT SHAFT BEARINGS

\begin{tabular}{|c|c|c|}
\hline Failure no. & Mission no. on failed shuttle & Cumulative fleet missions \\
\hline 1 & 22 & 88 \\
\hline 2 & 33 & 121 \\
\hline 3 & 42 & 139 \\
\hline 4 & 53 & 150 \\
\hline
\end{tabular}




\section{Figure Captions}

Fig. 1 Body flap actuator cross section showing input shaft bearings.

Fig. 2 Bearing test apparatus.

Fig. 3 Sketch of Weibull plot where (Weibull) slope or tangent of line is $e, S_{\beta}$ is probability of survival of 36.8 percent at which $L=L_{\beta}$ or $L / L_{\beta}=1$

Fig. 4 Damage to shuttle body flap actuator bearing inner race after 20 flights. (a) SEM view of wear band in race. (b) Cross section showing cracks below surface.

Fig. 5 Damage to test bearing at failure. (a) SEM view of wear band in race. (b) Cross section showing cracks below surface.

Fig. 6 Weibull plot of Series 2 mission spectrum tests at $24^{\circ} \mathrm{C}$. Failure index 3/6.

Fig. 7 Weibull plot of Series 1-2 mission spectrum tests at 60 and $24^{\circ} \mathrm{C}$. Failure index 3/12.

Fig. 8 Weibull plot of Series 3 tests at $24^{\circ} \mathrm{C}, 16-24 \mathrm{kN}$; and 50 and $80 \mathrm{rpm}$. Failure index 12/20.

Fig. 9 Weibull plot of Series 4 elevated temperature tests at $16 \mathrm{kN}$ load, 50 and $80 \mathrm{rpm}$. Failure index 3/6.

Fig. 10 Estimated life and reliability of input shaft bearings. 


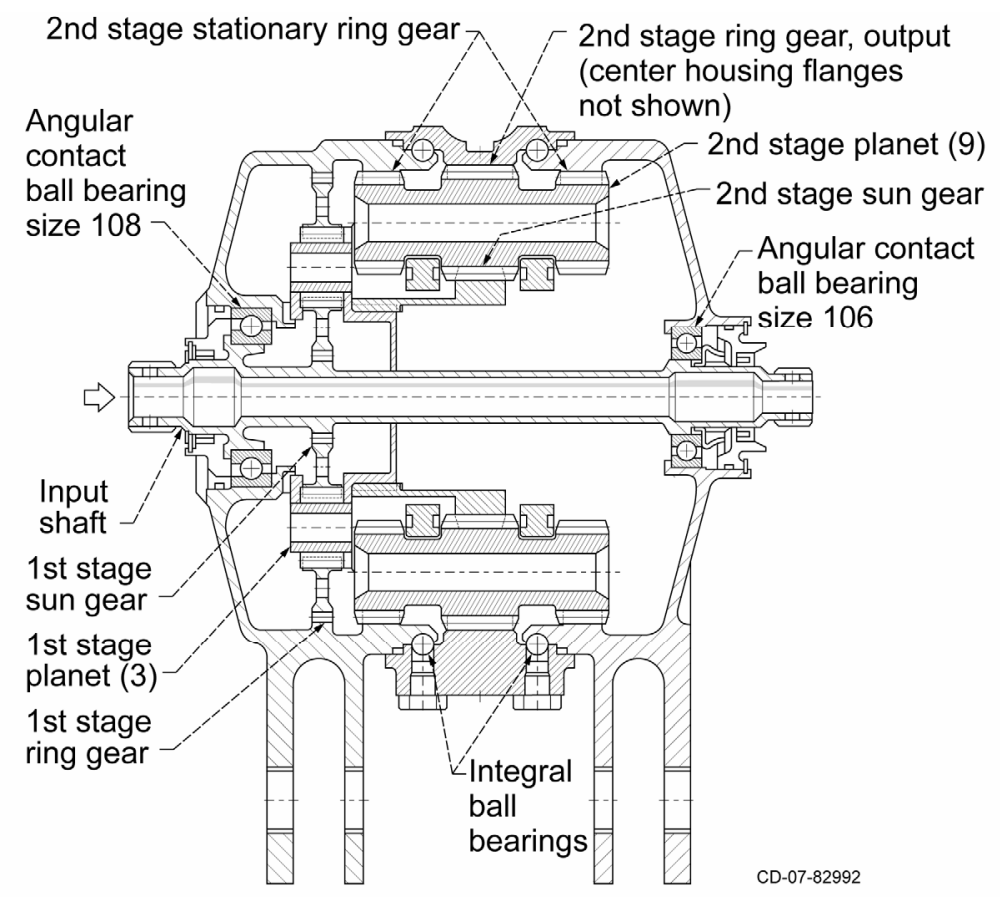

Figure 1.-Body flap actuator cross section showing input shaft bearings. 


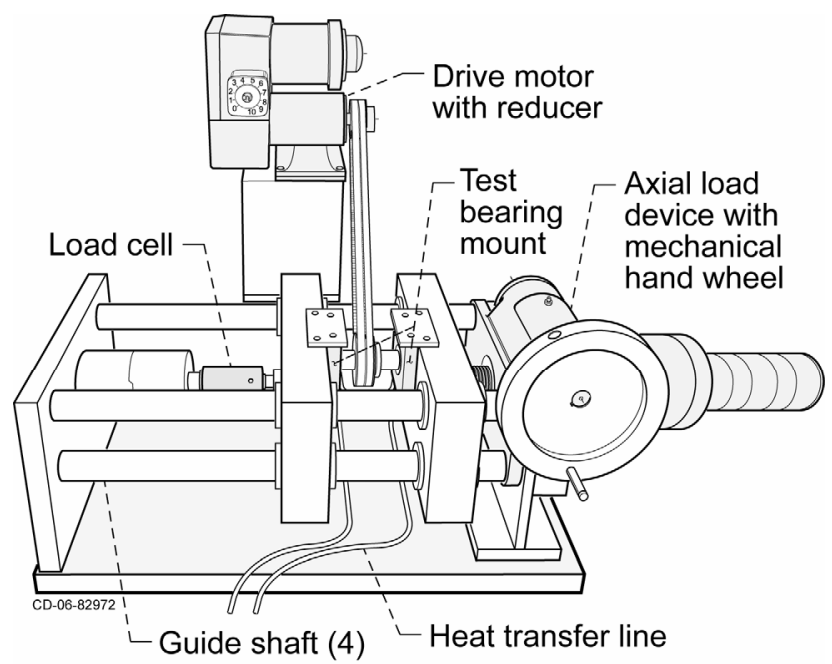

Figure 2.-Bearing test apparatus. 


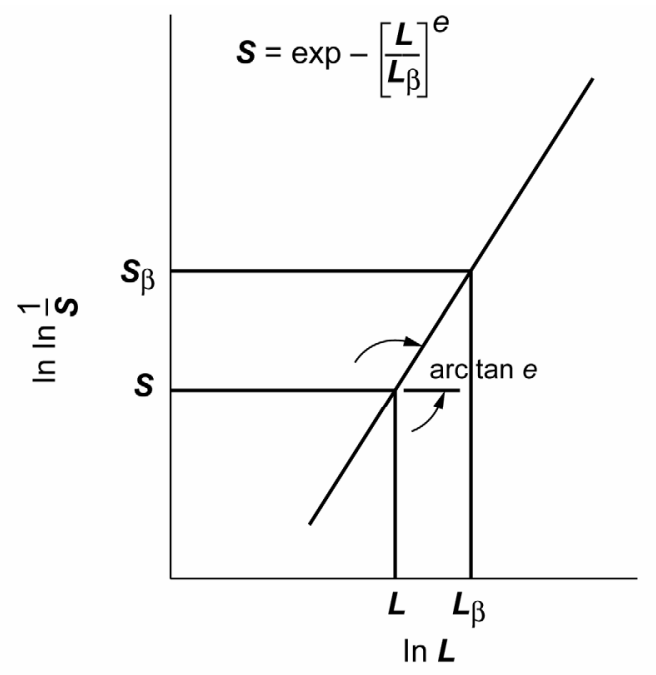

Figure 3.-Weibull plot where (Weibull) slope of tangent of line is $e$; probability of survival,

$S_{\beta}$, is 36.8 percent at which $L=L_{\beta}$ or $L / L_{\beta}=1$. 

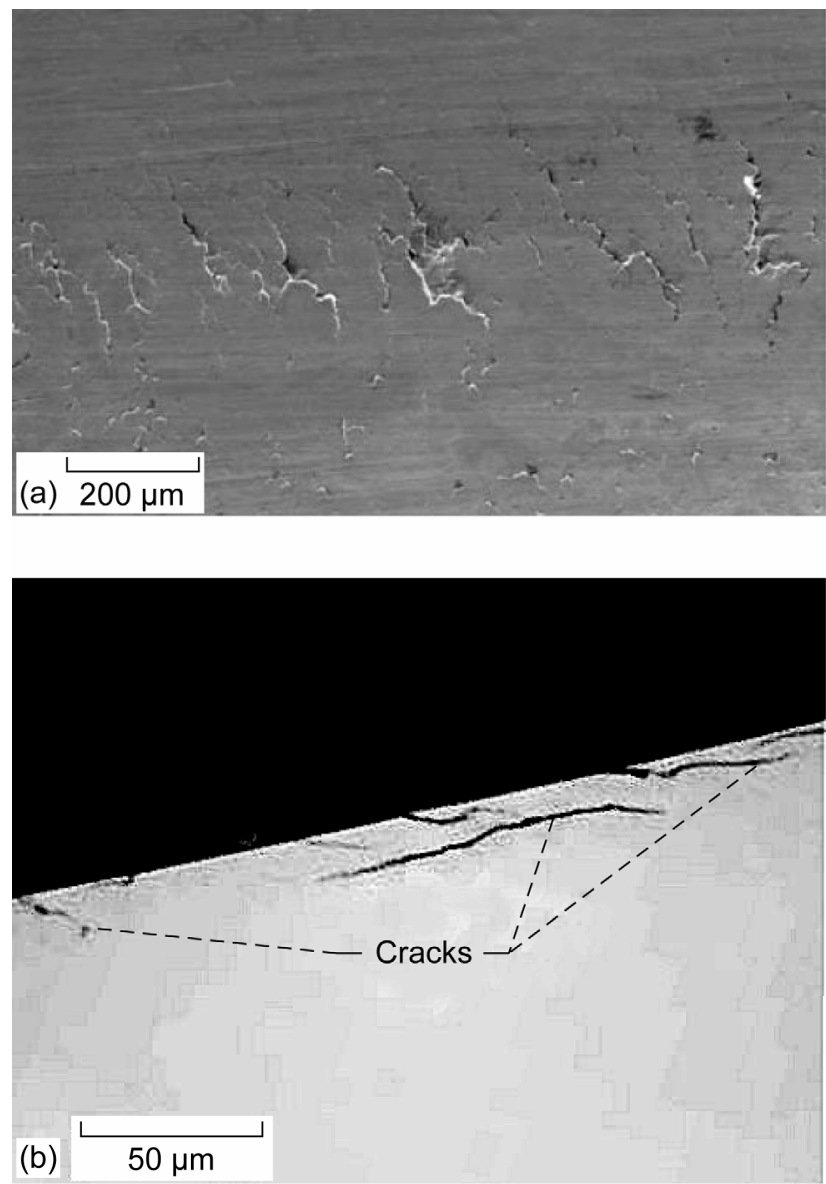

Figure 4.-Damage to shuttle body flap actuator bearing inner race after 20 flights. (a) SEM view of wear band in race. (b) Cross section showing cracks below surface. 


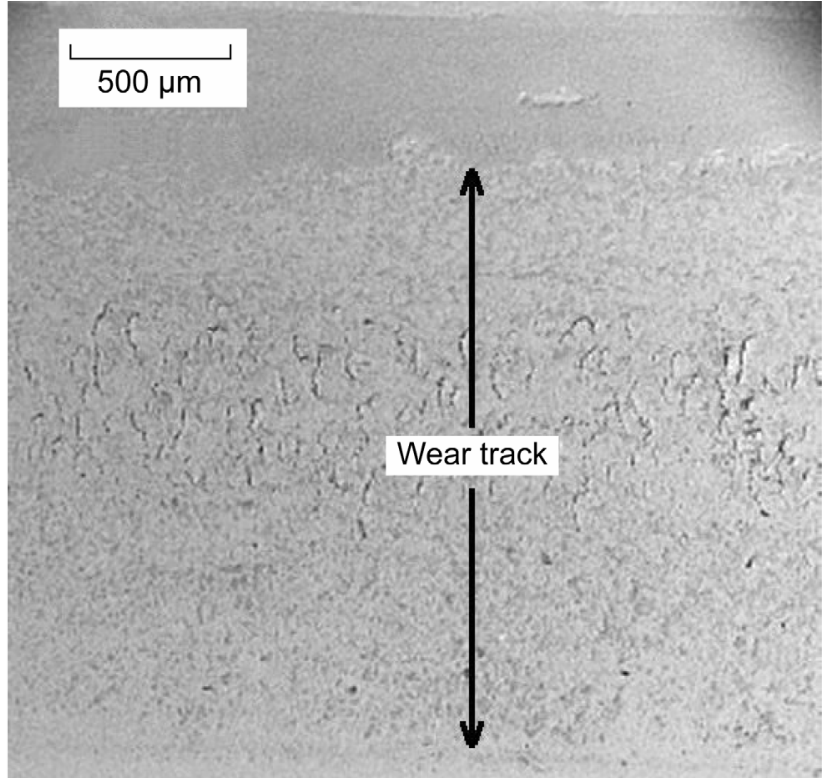

(a)

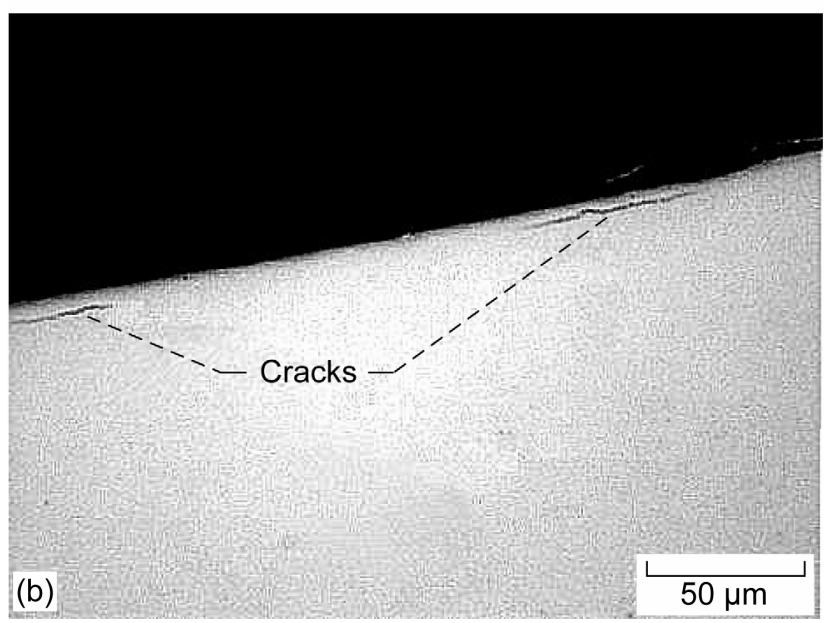

Figure 5.-Damage to test bearing at failure. (a) SEM view of wear band in race. (b) Cross section showing cracks below surface. 


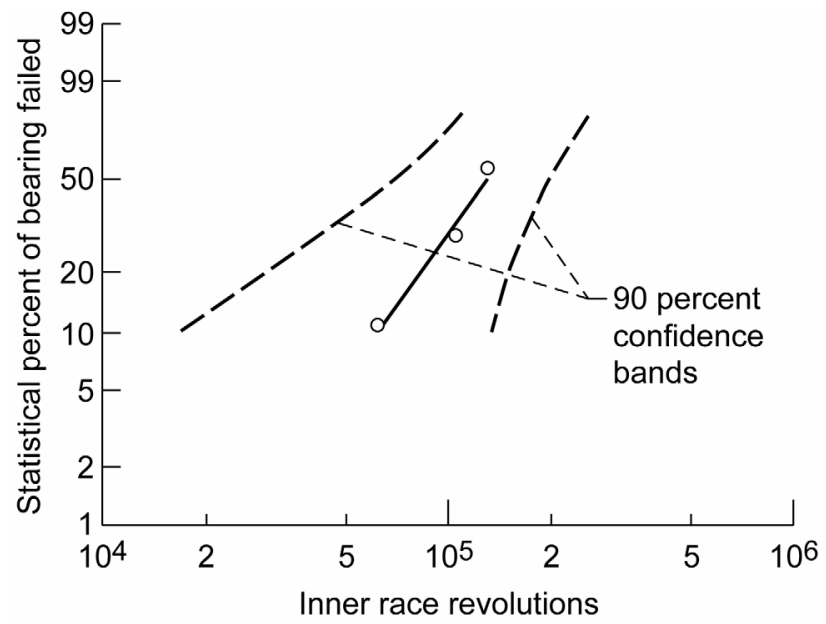

Figure 6.-Weibull plot of Series 2 mission spectrum tests at $24^{\circ} \mathrm{C}$. Failure index $3 / 6$. 


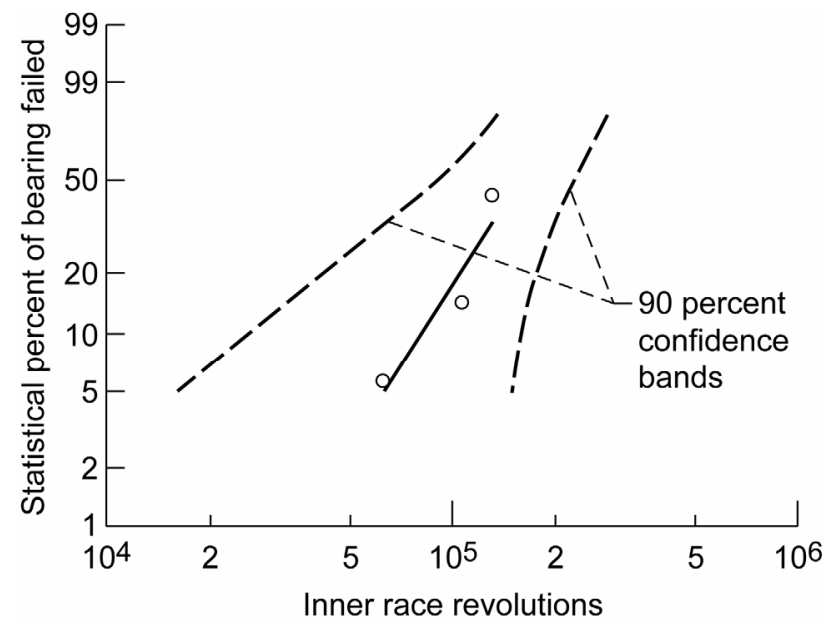

Figure 7.-Weibull plot of Series 1-2 mission spectrum tests at 60 and $24^{\circ} \mathrm{C}$. Failure index $3 / 12$. 


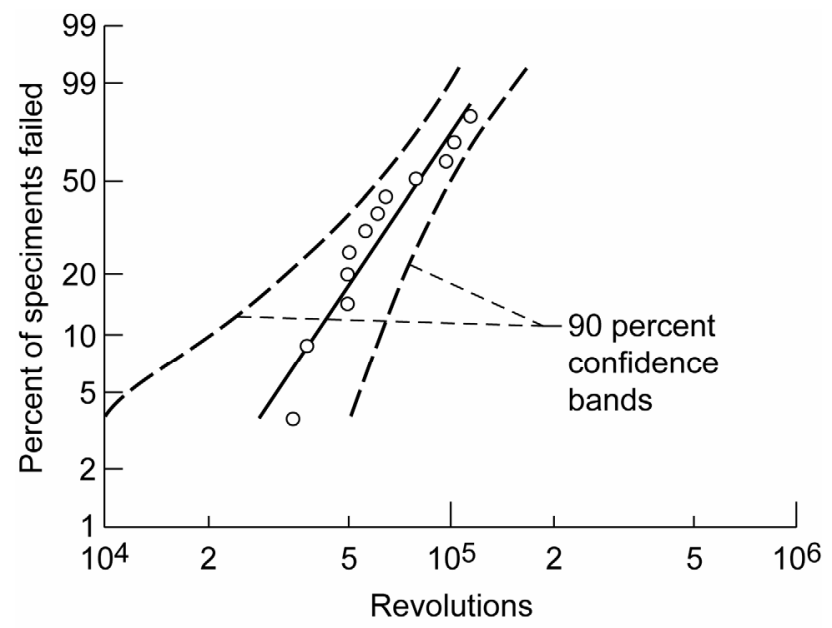

Figure 8.-Weibull plot of Series 3 tests at $24^{\circ} \mathrm{C}$, $16-14 \mathrm{kN} ; 50$ and $80 \mathrm{rpm}$. Failure index 12/20. 


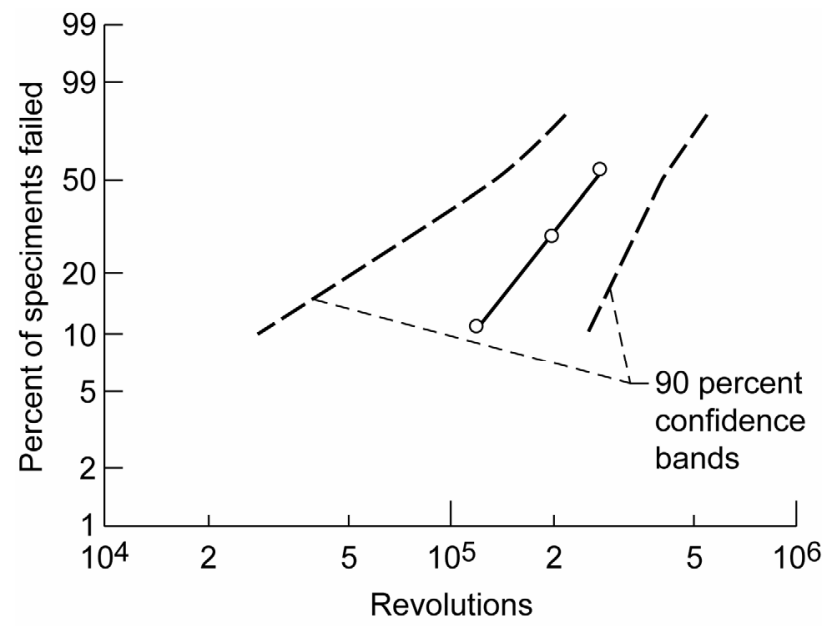

Figure 9.-Weibull plot of Series 4 elevated temperature tests at $16 \mathrm{kN}$ load, 50 and $80 \mathrm{rpm}$. Failure index 3/6. 


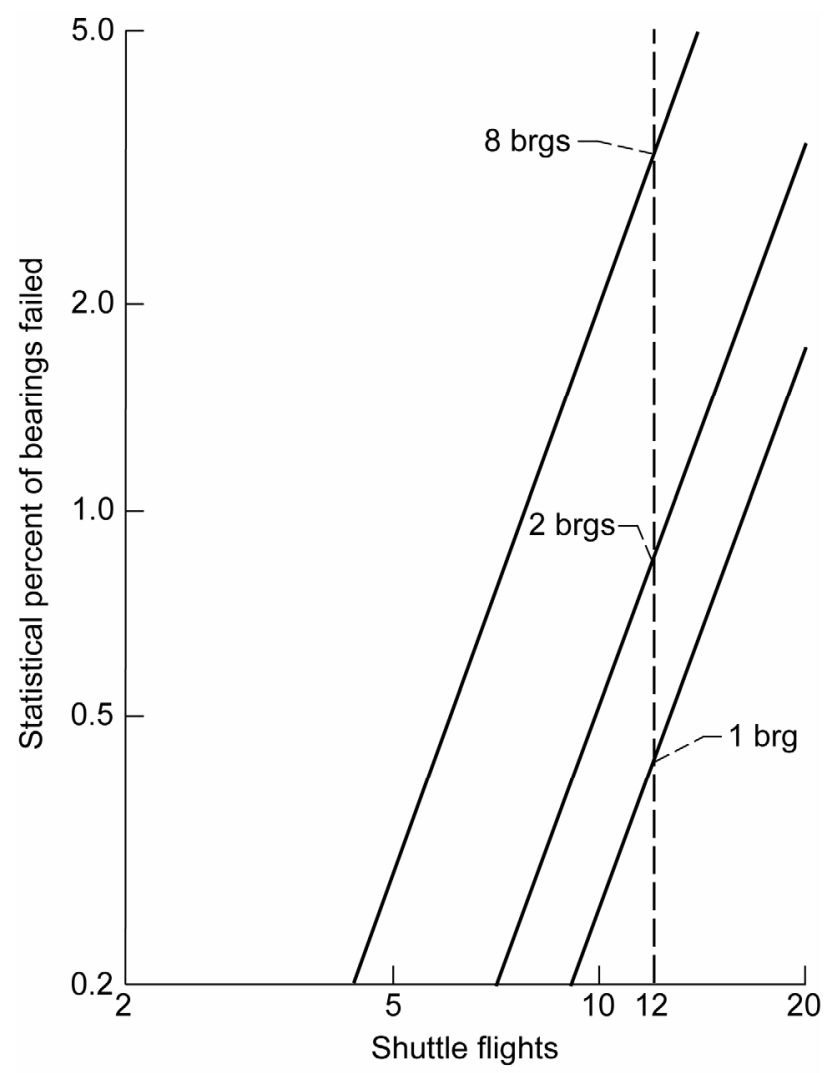

Figure 10.-Estimated life and reliability of input shaft bearings. 